\title{
Multiple effects of ice load changes and associated stress change on magmatic systems
}

Freysteinn Sigmundsson $^{(1)}$, Fabien Albino ${ }^{(1)}$, Peter Schmidt ${ }^{(2)}$, Björn Lund ${ }^{(2)}$, Virginie Pinel $^{(3)}$, Andrew Hooper ${ }^{(4)}$, Carolina Pagli ${ }^{(5)}$

(1) Nordic Volcanological Centre, Institute of Earth Sciences, University of Iceland, Askja, Sturlugata 7, Reykjavik, Iceland fs@ hi.is.

(2) Department of Earth Sciences, Uppsala University, Sweden

(3) ISTerre, IRD R219, CNRS, Université de Savoie, Le Bourget du Lac, France.

(4) Delft University of Technology, Delft, The Netherlands

(5) School of Earth and Environment, University of Leeds, UK.

\section{Summary}

Ice retreat on volcanoes reduces pressure at the surface of the Earth and induces stress changes in magmatic systems. The consequences can include increased generation of magma at depth, increased magma capture in the crust, and modification of failure conditions of magma chambers. We review the methodology to evaluate each of these effects, and consider the influence of ongoing ice retreat on volcanoes at the MidAtlantic divergent plate boundary in Iceland. Evaluation of each of these effects requires a series of assumptions regarding the rheology of the crust and mantle, and the nature of magmatic systems, contributing to relatively large uncertainty in response of a magmatic system to climate warming and associated ice retreat. Pressure release melting due to ice cap retreat in Iceland may at present times generate a similar amount of magma as plate tectonic processes; larger than realized previously. However, new modelling shows that part of this magma may be captured in the crust, rather than being erupted. Gradual retreat of ice caps do steadily modify failure conditions at magma chambers, which is highly dependent on their geometry and depth, as well as the details of ice load variations. A model is presented where long-term ice retreat at Katla volcano decreases the likelihood of eruption, as more magma is needed in the magma chamber to cause failure than in the absence of the ice retreat.

\section{Introduction}

The ongoing global warming drives retreat of ice caps and glaciers worldwide; many of which are located in volcanic regions. The reduced ice load on the surface of these volcanic areas modifies conditions in the subsurface by altering the stress field. The changes may include pressure decrease, possible rotation of the principal axes of the stress field and variation in differential stress. A review by Sigmundsson et al. (2010) is here complemented with additional considerations. The multiple effects of stress change at magmatic systems include (i) effects on melting conditions, (ii) influence on magma propagation and emplacement of dykes, and (iii) influence on magma storage zones. In principle, a model of ice unloading can be applied to an Earth model to evaluate each of these effects. In practise, there are many assumptions to be made in order to carry out such modelling based on limited constraints on both Earth and 
ice retreat models. This leads to large uncertainty on the exact response of a particular volcano to stress change induced by global warming. Complexity of a real volcano interior needs to be simplified in these models. Various petrological, geochemical and geophysical evidence shows that the crust underlying volcanoes is often not homogeneous and may rather contain localized magma storage zones. Here these storage zones are modelled as fluid filled cavities of simple geometries and referred to as magma chambers.

\section{Effects of glacial unloading on deep magma generation}

The amount of melt generated by glacial unloading depends on the pressure change and the relation between the pressure $P$ and the degree of melting by weight, here denoted $F$ (denoted by $X$ by McKenzie (1984) and Sigmundsson et al. (2010)). We follow Jull and McKenzie (1996) by assuming isentropic decompressional melting, where the material derivatives of degree of melting and pressure are related as

$$
\frac{D F}{D t}=\left(\frac{\partial F}{\partial P}\right)_{S}\left(\frac{\partial P}{\partial t}+\mathbf{v} \times \nabla P\right)
$$

where $\mathbf{v}$ is the velocity of the solid and $(\partial F / \partial P)_{S}$ is the partial derivative of the degree of melting with respect to pressure at a constant entropy. This equation needs to be evaluated within a melting regime in the mantle. There are thus three important steps for evaluating the total amount of melt generated in the mantle by deglaciation in a particular volcanic area. These steps are (i) evaluating the pressure change at depth, (ii) evaluating what relation to use for pressure versus melting, and (iii) estimating the geometry and extent of the melting regime, in order to know where to carry out integration of the deglaciation induced melting process. All these steps are important when evaluating the deep magma generation caused by glacial unloading. We consider them below for the cause of the ongoing deglaciation of Iceland since 1890 caused by climate warming.

An earlier study has evaluated mantle melting due to ongoing retreat of only the largest ice cap in Iceland, Vatnajökull (Pagli and Sigmundsson, 2008). A study by Arnadottir et al. (2009) revealed, however, that present geodetically measured uplift rates of $10-23 \mathrm{~mm} / \mathrm{yr}$ in central Iceland cannot be produced by deglaciation of Vatnajökull alone. Contributions from the smaller ice caps in Iceland are significant. In order to improve the estimate of deep melt generation under Iceland in response to the present deglaciation we employed a refined version of the ice model by Arnadottir et al. (2009), including the five largest ice caps at a spatial resolution of $2 \times 2 \mathrm{~km}$. The deglaciation rates in the model are based on the estimated $435 \mathrm{~km}^{3}$ ice loss of Vatnajökull between 1890 and 2004 used by Pagli et al. (2007), and the mean annual mass balance between the years 1991/92 and 2005/06 (Björnsson and Palsson, 2008). We linearly extend the ice model to cover the period 1890-2010 (120 model years). This refined ice retreat model yields a slight improvement in the fit of the predicted vertical uplift rates to the GPS measurements reported by Arnadottir et al. (2009). We used this ice model in a three-dimensional model of GIA related decompressional melting, rather than in an axisymmetric model presented by Sigmundsson et al. (2010). For Earth model, we 
use the preferred model of Arnadottir et al. (2009) presented in Table 1. The uppermost layer in this model isa $10 \mathrm{~km}$ thick elastic layer which we refer to as the elastic layer or upper lithosphere. Below this is a $30 \mathrm{~km}$ thick viscoelastic layer of $10^{20} \mathrm{~Pa}$ sviscosity; the viscoelastic layer or lower lithosphere. Beneath is the mantle, modeled as a viscoelastic half space of viscosity $10^{19} \mathrm{~Pa} \mathrm{~s}$.

In order to estimate the total increase in melt production due to deglaciation, we use a similar triangular cross $^{-}$section melting region as previously used by Jull and McKenzie (1996) and Pagli and Sigmundsson (2008). However, in our three-dimensional model the melting region traces the Eastern Volcanic Zone of Iceland south of the Vatnajökull ice cap and the Northern Volcanic Zone to the north of Vatnajökull (Figure 1). The length of the melting regime considered is approximately $340 \mathrm{~km}$. Both Jull and McKenzie (1996) and Pagli and Sigmundsson (2008) assumed a triangular shaped melting regime, with a ridge angle of $45^{\circ}$, in accordance with an assumption of passive upwelling and corner flow. However, the volcanic zones in Icelandare neither straight nor perfectly perpendicular to the direction of spreading, and the upwelling beneath Iceland in the presence of the mantle plume is unlikely to be governed by passive upwelling (Maclennan et al., 2002). Therefore, ridge angles of 45, 60 and 70 degrees were considered here.

During the 120 years of the model run, the decompression rates vary about $\pm 10 \%$, but we consider the average values. Figure 1 shows the predicted GIA decompression at selected depths of the melting region. In the mantle, the decompression reaches $1390 \mathrm{~Pa} / \mathrm{yr}$ at $43 \mathrm{~km}$ depth beneath the centre of unloading, while at $109 \mathrm{~km}$ depth it is approximately $500 \mathrm{~Pa} / \mathrm{yr}$. In the lowermost part of the lower viscoelastic lithosphere, pressure increases by up to $660 \mathrm{~Pa} / \mathrm{yr}$ beneath Vatnajökull.

The pressure change values form the basis for estimating the associated melt generation, but various forms of the relation between the two have been suggested. Here we have obtained $\partial F / \partial P$ by integrating equation D7 of McKenzie (1984) and the melt parametrization by McKenzie and Bickle (1988), from the solidus pressure. As we are interested in the melt volume due to ice removal we have to convert $F$, the degree of melting by weight, to $\phi$ ? the degree of melting by volume (McKenzie (1984) refers to $\phi$ ? $\square$ as the porosity).

$$
d \phi=\frac{\rho_{l} \rho_{s}}{\left(F \rho_{s}+(1-F) \rho_{l}\right)^{2}} d F
$$

Here $\rho_{\mathrm{l}}$ is the density of the melt and $\rho_{\mathrm{s}}$ is the density of the solid. In contrast to the melt parametrization given by equation D8 of McKenzie (1984), which was used by Pagli and Sigmundsson (2008) in their study of glacially induced melting, the melt parametrization by McKenzie and Bickle (1988) does not yield a constant magnitude of $\partial \phi / \partial P$. Assuming a potential temperature of $1500^{\circ} \mathrm{C}$, which yields a solidus depth of approximately $112 \mathrm{~km}, \partial \phi / \partial P$ attains its largest magnitude of about $-0.132 \mathrm{GPa}^{-1}$ at a depth of approximately $100 \mathrm{~km}$ and decreases to a magnitude of about $-0.048 \mathrm{GPa}^{-1}$ at the surface. The rate of degree of melting per volume is then given by the pressure change $\partial P / \partial$ multiplied by $\partial \phi / \partial P$.

Integration from solidus depth to the base of the lithosphere (40 km depth) yields melt production rate estimates of $0.17,0.11$, and $0.07 \mathrm{~km}^{3} / \mathrm{yr}$ for ridge angles of $45^{\circ}, 60^{\circ}$, and $70^{\circ}$ respectively (Figure 2). A crude estimate of the steady state melt production rate beneath Iceland can be obtained from the 
product of the mean thickness of the crust, the length of the spreading ridge and the full spreading velocity. Assuming, as Pagli and Sigmundsson (2008), a mean thickness of $30 \mathrm{~km}$, a length of the ridge of $300 \mathrm{~km}$ and a full spreading velocity of $19 \mathrm{~mm} / \mathrm{yr}$, the melt production rate would be $0.17 \mathrm{~km}^{3} / \mathrm{yr}$. Note that this would be a minimum melt production rate as more melt could be produced in the mantle but not extracted to form crust. For a steady melt production rate of $0.17 \mathrm{~km}^{3} / \mathrm{yr}$, the inferred increase in melting due to present deglaciation would by $41-100 \%$. This indicates that melt generation due to ongoing deglaciation of Iceland is presently of a similar magnitude as the plate tectonic melt production.

\section{Influence on magma capture in the crust}

Although a very significant volume of new magma is generated at depth in the mantle, it is uncertain if and when it reaches the surface of the Earth and is erupted. The rate of melt extraction from depth to the surface is uncertain. An average melt extraction velocity of $>50 \mathrm{~m} / \mathrm{yr}$ would suggest a transport time ofless than 1000 years from a depth of $50 \mathrm{~km}$. Here we consider another effect, namely, if part of the magma generated by deglaciation will be captured by the crust and form intrusions, rather than feeding eruptions, as evaluated by Hooper et al. (2011).

The ascent of magma through the crust is driven primarily by buoyancy forces, which lead to opening of fractures above (e.g., Lister and Kerr, 1991). In an isotropic stress field, fractures below can contract as magma is squeezed upwards. However, if the principal components of the stress field within the crust are unequal, they are relaxed by non-reversible opening of the magma-filled fractures. Hence extensional stress environments favour intrusion over eruption (e.g., Segall et al., 2001). In general, the opening of a dyke scales with the excess dyke pressure $\Delta P_{d y k e}$. For example, a circular crack with uniform excess pressure has volume

$$
V=\frac{8 a^{3}(1-v)}{3 \mu} \Delta P_{d y k e}
$$

where $a$ is the radius vis the Poisson'sratio, and $\mu$ is the shear modulus (Segall, 2009). In the case where magma can flow until equilibrium pressure conditions are reached, the excess pressure is equal to the difference between the mean stress and the stress normal to the fracture.It follows that themagma volume that can be accommodated by the relaxation of the deviatoric stress in dykes is proportional to this excess pressure:

$$
V \propto \Delta P_{d y k e}=\frac{1}{3}\left(\sigma_{1}+\sigma_{2}+\sigma_{3}\right)-\sigma_{n}
$$

where $\sigma_{1}, \sigma_{2}$ and $\sigma_{3}$ are the principal stresses in descending order of strength, and $\sigma_{\mathrm{n}}$ is the fracture-normal stress.

In Iceland, spreading across the rift zones, of $19.7 \mathrm{~mm} / \mathrm{yr}$ (Demets et al. 1994), is the primary contributor to $\Delta$ Pn the crust, but changes in the ice load also affect it. Here we estimate the contribution to $\Delta P$ from the reduction in mass of Icelandic ice caps since glacial retreat began circa 1890 (Figure 3). We use the sameEarth model from Árnadóttir et al. (2009), which consists of a $40 \mathrm{~km}$ thick lithosphere overlying a Maxwell halfspace with viscosity $10^{19} \mathrm{~Pa} \mathrm{~s}$. The results are, however, not particularly sensitive to the Earth model used (Hooper et al., 2011). We calculate $\Delta P_{d y k e}$ for two different scenarios, the first when a dyke is 
perpendicular to $\sigma_{3}$ induced by the melting ice cap and the second when the dyke is parallel with the rift zone (Figure 3). We see that whether intrusion is encouraged or discouraged depends on dyke orientation, although away from the edges of the ice cap, intrusive activity is always favoured. It is usually assumed that dykes propagate perpendicular to the direction of $\sigma_{3}$ and that $\sigma_{3}$ in this region is dictated by plate spreading, in which case the second scenario should apply.

This modelling has been put in context with an unusual dyke intrusion in the lower crust in Iceland in 2007-2008, in the Upptyppingar area north of the Vatnajökull ice cap. The dyke instrusion was captured well by satellite radar interferometric observations and Global Positioning System geodetic measurements (Figure 4). The geodetic study (Hooper et al., 2011) concludes that the strike and dip of the dyke are $81^{\circ}-84^{\circ}$ and $42^{\circ}-43^{\circ}$, in good agreement with the seismic studies (Jakobsdóttir et al., 2008; White et al. 2011). The geodetic study allows the estimate of the magma volume involved;42-47 millon $\mathrm{m}^{3}$ at $95 \%$ confidence. The orientation of this dyke intruded 2007-2008 into the lower crust near the largest ice cap in Iceland actually agrees well with it being perpendicular to $\sigma_{3}$ induced by the melting ice cap. The dyke is not parallel with the rift zone. This raises the question of whether the stress field there is actually dominated by the melting ice cap. For the Upptyppingar intrusion, although the orientation of the dyke is perpendicular to $\sigma_{3}$ induced by the melting ice cap, the displacement along the dyke plane consists both of shearing and opening, indicating that actually the stress field is dominated by the plate tectonic process (Hooper et al., 2011).

\section{Influence on shallow magma chambers}

Pressure inside magma chambers, here denoted $P_{\mathrm{c}}$, increases by flow of magma into the chamber from deeper melting sources, or by magma crystallization. When the pressure reaches a critical value, here denoted $P_{\mathrm{r}}$, tensile rupture of the reservoir wall will occur and magma is transported towards the Earth's surface, eventually leading to an eruption (Albino et al., 2010). Any stress perturbations around a magma chamber cause a pressure change within it, $\Delta P_{\mathrm{c}}$, as well as a modification of the critical pressure value to initiate tensile fractures, $\Delta P_{\mathrm{r}}$. An unloading event at the surface of a volcano always induces a magma pressure decrease within the chamber. The amplitude of this pressure drop is largest for incompressible magmas and decreases for more compressible magmas (Pinel and Jaupart, 2005). However, as previously shown by Albino et al. (2010), the threshold pressure for dyke initiation $P_{\mathrm{r}}$ can either increase or decrease according to the geometry of the magma chamber and the surface unloading event. In all cases, the difference in the two terms, $\Delta P_{\mathrm{r}}-\Delta P_{\mathrm{c}}$, provides the relative evolution of a volcanic system between the initial and the final state and characterizes the effect of the surface perturbation on the ability of the system to erupt. A negative value signifies that the magma reservoir state moves closer to rupture conditions and eruption probability increases. Conversely, if the sign is positive, the magma reservoir evolves further away from its failure state and the likelihood of an eruption is reduced.

We have previously performed two dimensional numerical simulations to quantify the effect of short-term unloading events on idealized magma chambers of simple shapes (sphere and ellipsoids) filled with an inviscid fluid embedded in an elastic homogeneous crust (Albino et al., 2010 ; Sigmundsson et al., 2010). We 
showed, that either enhancement or reduction of eruption likelihood will occur as described above, depending on the magma chamber geometry, the magma compressibility as well as the spatial distribution of the surface load. A central unloading event occurring directly above a prolate reservoir will inhibit rupture initiation whereas the same event above a spherical or oblate reservoir will promote rupture. In the latter case, for the spherical shape, the triggering effect is maximal, and equal to the amplitude of the removed load.

This elastic model was applied to the Icelandic volcano, Katla, covered by the Mýrdalsjökull ice cap. This ice cap shows load variations at two different time-scales: (i) an annual load cycle in the centre part, with a difference up to 6 meters in snow thickness from winter to summer, and (ii) a long-term ice thinning at the periphery due to global warming, with a rate around $4 \mathrm{~m} / \mathrm{yr}$ (Gudmundsson et al. 2007). For annual cycles, our elastic model predicts that, in the case of a spherical or horizontally elongated magma reservoir, eruptions at Katla are more likely when the seasonal snow cover at Mýrdalsjökull is smallest (Albino et al. 2010). This triggering effect is small, around a few kilopascals, but appears consistent with the fact that all the last nine known historical eruptions at Katla occurred during the warm season (e.g., Eliasson et al. 2006).

When considering surface load variation distributed over large areas or acting over a long periods as obviously the case for ice retreat, it becomes necessary to take into account the viscous response of the upper mantle and lower crust to fully evaluate the potential effect on magma reservoirs. This has not been considered before in our models. Based on this consideration, we performed a series of axisymmetrical numerical models considering an upper elastic crust surrounding the magma reservoir and a lower medium characterized by a viscoelastic behaviour (Figure 5). The whole medium is submitted to gravity field and a buoyancy stress, $\sigma_{\mathrm{B}}$, that acts at the bottom of the elastic medium when this discontinuity is displaced. Buoyancy stress is related to the vertical displacements of the interface between both media through the following relation:

$$
\sigma_{B}=\rho_{m} g U_{z}
$$

where $\rho_{\mathrm{m}}$ is the mantle density, and $U_{\mathrm{z}}$ the vertical displacement.

Solutions for the initial elastic response and the fully relaxed state, in absence of magma reservoir, were validated using analytical solutions provided by Pinel et al, 2007. As initial state, we take the fully relaxed state obtained after applying a constant magmatic pressure within the reservoir. We then apply a surface unloading, at a constant rate, over a given period of time. Failure of the magma reservoir will occur when the minimal compressive deviatoric stress, $\delta \sigma_{3}$, reaches the value of the rock tensile strength, $T_{\mathrm{s}}$. For a whole range of magmatic pressure, we then calculate the temporal evolution of the parameter $\delta \sigma_{3}$ at each time step and compare to the tensile strength value. From these results, we are able to derive the threshold pressure $P_{\mathrm{r}}$ required for dyke initiation at each time step.

As all surface unloading events, a long term ice thinning does induce a magma pressure decrease, acting to move the system away from rupture conditions. However, such magma pressure evolution can easily be compensated by magmatic processes not considered in our model, as for example magma feeding from deep sources or even magma crystallisation.As for the elastic case, the pressure required to initiate intrusions from a magma chamber may either increase, indicating that the system is 
moving away from eruption conditions, or decrease, corresponding to an increase of eruption likelihood. The behaviour is always highly dependent on the geometry of the magma reservoir, the spatial distribution of the surface load and also its temporal evolution.

We applied our model to Katla Volcano in order to estimate the long term influence of Mýrdalsjökull's ice thinning using the set of parameters listed in Table 2. Viscosity of the lower medium is set at $3 \times 10^{18}$ Pas, consistent with volcanic systems being warmer and less viscous than their surroundings. Lithosphere thickness was here set at $10 \mathrm{~km}$, same as the elastic upper lithosphere in the regional GIA study. For reservoir geometry and unloading distribution, we consider the same set of parameters as in the previous elastic study (Albino et al., 2010). Magma was considered incompressible. After a large advance during the Little Ice Age, Mýrdalsjökull, as all the glaciers in Iceland, started to retreat around 1890 (Björnsson, 1979). We thus model the Mýrdalsjökull retreat by applying a constant unloading rate of $35 \mathrm{kPa} / \mathrm{yr}$ (corresponding to a 4 meters loss of ice), at the periphery of the ice capat distances between 7 and $17 \mathrm{~km}$ from the centre of the ice cap, as used by Albino et al. (2010). This unloading is applied over the last 120 years; from 1890 to present.

Figure 6a shows the resulting temporal evolution of the failure pressure change, $\Delta P_{\mathrm{r}}$. The threshold pressure increases gradually during the unloading period. The cumulative change reaches $0.34 \mathrm{MPa}$, which corresponds to around $7 \%$ of its initial failure pressure (the initial value in the model was $4.87 \mathrm{MPa}$ and corresponds to the state before the unloading). This behaviour with an increase of failure pressure in the viscoelastic model is opposite to that compared to a fully elastic model, where decrease is inferred (see Figure 6a). For magma pressure, both models, elastic and viscoelastic, predict a pressure decrease inside the Katla magma chamber (Figure 6b). By taking into account the viscous effect of lower crust, the rate of the magma pressure drop is larger than for the elastic model, with a difference about $0.1 \mathrm{MPa}$ after 120 years. By evaluating the relative difference between both pressure changes, $\Delta P_{\mathrm{r}}-\Delta P_{\mathrm{c}}$, (Figure 6c), we are able to conclude if the probability of dike injection from the Katla magma chamber will increase or decrease due to a century of icecap retreat at Mýrdalsjökull. The difference is positive, indicating that the cumulative change due to ice retreat may lead to a reduction of the eruption probability. The preventing effect on reservoir failure reaches an amplitude up to $1 \mathrm{MPa}$ at the present time, after 120 years of icecap deglaciation. This may cause longer time between eruptions, and larger storage of magma in the chamber, available for eruptions.The rate of change in the failure conditions is more pronounced in the later part of the icecap evolution, suggesting that modulation of magmatic activity may be larger after few decades of consecutive retreat rather than when the retreat begins. The results presented here indicate the importance of taking into consideration viscous relaxation of the upper crust and the mantle for long-term unloading event, such as ice retreat, when considering their effects on shallow magma chambers. Indeed, results obtained are quite different if the Earth model is assumed to be fully elastic instead of viscoelastic, leading to a large underestimation of the effects of pressure variation in the case presented above.

\section{Discussion and conclusions}

The analyses presented here reveal some differences compared to earlier summary of Sigmundsson et al. (2010) of the stress induced effects of unloading both on deep 
mantle melting and its influence on crustal magma chamber. The third effect presented above, on the increased magma capture in the crust was not considered in the previous overview. Regarding the influence on deep mantle melting due to present thinning of the Vatnajökull ice cap in Iceland, Pagli and Sigmundsson (2008) estimated that additional magma was generated at a rate of about $0.014 \mathrm{~km}^{3} / \mathrm{yr}$ underneath Vatnajökull. The model calculations presented here suggest, however, a value of $0.07-0.17 \mathrm{~km}^{3} / \mathrm{yr}$ for the whole of Iceland's rift zones, or about an order of magnitude more. There are four factors contributing to this difference, the first one being the area of study. The earlier study considered only the rift under Vatnajökull, but here we consider the full length of the rift zone across Iceland. This difference in the length of the rift considered contributes about a factor 3 . A second contributor is the consideration of all the ice caps in Iceland rather than just the Vatnajökull ice cap. The smaller ice caps (Figure 1) are also retreating and generally at a speed equal to the higher peripheral rates at Vatnajökull, adding about 50\% to the weight loss compared to Vatnajökull alone. They also spread the pressure decrease over a wider geographic area, stimulating pressure decrease deep in the melting regime. An additional contributor to the high value of present day deglaciation induced mantle melting presented here is the use of the relation between pressure change and melting by McKenzie and Bickle (1988) rather than McKenzie (1984). Finally, the ridge angle and assumed depth of melting also influence the estimated melt volumes.

Despite the larger amount of melt generated under Iceland by ice unloading in present models, there is a large uncertainty in how much of this magma arrives at the surface of the Earth, and when it does so. Melt extraction rates from the mantle are finite and uncertain; and it may require decades or centuries for magma to travel from the melting regime to the surface. Furthermore, the excess melt generated by ice unloading will not arrive at the surface all at the same time, rather over a distributed time interval as comes from variable depth. On the way towards the surface, the additional magma may be captured by the crust as explained in chapter 3 , as the deglaciation can induce higher excess pressure in dykes, driving their formation. This allows more magma to be emplaced in the crust as dykes than in the absence of deglaciation. A deep dyke injection north of the Vatnajökull ice cap in Iceland 20072008 may have been influenced by the stress field deep in the crust, generated by ice retreat.

Finally, we have considered the influence of viscoelastic response of crust and mantle to long term ice retreat on stability of shallow magma chambers. The effects are very dependent on the geometry of magma chambers and ice unloading. The inferred response of the unloading on the magmatic systems can be significantly larger when viscoelastic effects of crust and mantle are evaluated, compared to that which elastic modelling would indicate. The effects will, however, not in all cases to increase the probability of eruptions in all cases. For an oblate ellipsoidal model of the magma chamber at Katla volcano in Iceland, and an ice retreat model for the overlying Mýrdalsjökull ice cap consisting only of peripheral unloading at the ice cap edge as explained above, the effect of the reduction in the ice load will be to inhibit eruptions. Such effects could contribute to the present longer-than-average repose interval between major eruptions at this volcano breaking the ice cover. The most recent such eruption occurred in 1918, whereas prior to that the volcano has had major eruptions about 1-3 times per century since the 12th century. In addition to the complications presented above in accurately evaluating the effects of climate driven stress change on magmatic systems, there are other ways ice unloading can affect 
magmatic systems. Ice load variation can influence the likelihood of ring fault formation at volcanoes (Geyer et al., 2011) and unloading can influence a delicate balance of dissolved volatiles in magma residing in shallow magma chambers. More modelling and evaluation of the effects of surface unloading on magmatic systems are therefore needed, as well as good monitoring and surveying of ice capped volcanoes experiencing ice retreat.

\section{References}

Albino, F., Pinel, V. \& Sigmundsson, F., 2010 Influence of surface load variations on eruption likelihood: application to two Icelandic subglacial volcanoes, Grímsvötn and Katla, Geophys. J. Int., 181, 1510-1524. (doi: 10.1111/j.1365246X.2010.04603.xdoi)

Árnadóttir, T., Lund, B., Jiang, W., Geirsson, G., Björnsson, H., Einarsson, P. \& Sigurdsson, T. 2009 Glacial rebound and plate spreading: Results from the first countrywide GPS observations in Iceland, Geophys. J. Int., 177, 691-716. (doi: 10.1111/j.1365-246X.2008.04059)

Björnsson, H., 1979 Glaciers in Iceland, Jökull, 29, 74 - 80.

Björnsson, H. \& Pálsson, F., 2008 Icelandic glaciers, Jökull, 58, 365-368.

Björnsson, H., Pálsson, F., \& Haraldsson, H. H., 2002. Mass balance of Vatnajökull (1991-2001) and Langjökull (1996-2001), Iceland, Jökull, 51, 75-78.

Eliasson J., Larsen G., Gudmundsson M. T. \& Sigmundsson, F. 2006 Probabilistic model for eruptions and associated flood events in the Katla caldera, Iceland, Computational Geosciences, 10, 179-200. (doi:10.1007/s10596-005-9018-y)

Fleming, K., Martinec, Z. $\square \square$ Wolf, D., 2007. Glacial-isostatic Adjustment and the Viscosity Structure Underlying the Vatnajokull Ice Cap, Iceland, Pure App. Geophys., 164, 751-768.

Geyer, A. \& Bindeman, I. 2011 Glacial influence on caldera-forming eruptions, $J$. Vocanol. Geotherm. Res., 202, doi:10.1016/j.jvolgeores.2011.02.001

Gudmundsson, M. T., Hognadottir, P., Kristinsson, A. B. \& Guðbjornsson, S. 2007 Geothermal activity in the subglacial Katla caldera, Iceland, 1999-2005, studied with radar altimetry, Annals of Glaciology, 45, 66-72.

Gudmundsson, S., Björnsson, H., Magnusson, E., Berthier, E., Palsson, F., Gudmundsson, M.T., Högnadottir, T. \& Dall, J., 2011. Response of Eyjafjallajökull, Torfajökull and Tindfjallajökull ice caps in Iceland to regional warming, deduced by remote sensing, Polar Research, 30, 7282.

Hooper, A., Ofeigsson, B., Sigmundsson, F., Lund, B., Einarsson, P., Geirsson, H. \& Sturkell, E., 2011. Increased capture of magma in the crust promoted by ice-cap retreat in Iceland, Nature Geoscience, published online 25. Sept. 2011 (doi:10.1038/ngeo1269).

Jull, M. \& McKenzie, D. 1996 The effect of deglaciation on mantle melting beneath Iceland, J. Geophys. Res., 101, 21,815-21,828.

Lister, J. R. \& Kerr, R.C. 1991 Fluid-mechanical models of crack propagation and their application to magma transport in dykes. J. Geophys. Res. 96, 10,04910,077 .

Maclennan, J., Jull, M., McKenzie, D., Slater, L. \& Grönvold, K. 2002 The link between volcanism and deglaciation in Iceland, Geochem. Geophys. Geosyst., 3, 1062. (doi:10.1029/2001GC000282)

McKenzie, D. 1984 The generation and compaction of partially molten rock, $J$. 
Petrol., 25, 713-765.

McKenzie, D. and Bickle, M. J. 1988. The Volume and Composition of Melt Generated by Extension of the Lithosphere, J. Petrology, 29, 625-679.

Pagli, C., and Sigmundsson, F. 2008 Will present day glacier retreat increase volcanic activity? Stress induced by recent glacier retreat and its effect on magmatism at the Vatnajökull ice cap, Iceland, Geophys. Res. Lett., 35, L09304. (doi:10.1029/2008GL033510).

Pagli, C., Sigmundsson, F., Lund, B., Sturkell, E., Geirsson, H., Einarsson, P., Arnadottir, Th. \& Hreinsdottir, S. 2007 Glacio-isostatic deformation around the Vatnajökull ice cap, Iceland, induced by recent climate warming: GPS observations and finite element modeling, J. Geophys. Res., 112, B08405. (doi:10.1029/2006JB004421)

Pinel, V. \& Jaupart, C. 2005 Some consequences of volcanic edifice destruction for eruption conditions, J. Volc. Geotherm. Res., 145, 68-80. (doi:10.1016/j.jvolgeores.2005.01.012)

Pinel, V.,F. Sigmundsson, F., Sturkell, E., Geirsson, H., Einarsson, P., Gudmundsson, M. T. \& Högnadóttir, Th. 2007 Discriminating volcano deformation due to magma movement and variable loads: Application to Katla subglacial volcano, Iceland, Geophys. J. Int., 169, 325-338. (doi:10.1111/j.1365-246X.2006.03267.x)

Segall, P., Cervelli, P., Owen, S., Lisowski, M., \& Miklius, A. 2001 Constraints on dike propagation from continuous GPS measurements. J. Geophys. Res., 106, 19,301-19,318.

Segall, P. 2009 Earthquake and Volcano Deformation, Princeton University Press.

Sigmundsson, F., Pinel, V., Lund, B., Albino, F., Pagli, C., Geirsson, H., \& Sturkell, E. 2010.Climate effects on volcanism: influence on magmatic systems of loading and unloading fromice mass variations, with examples from Iceland, Phil. Trans. $R$. Soc. A, 368, 2519-2534. (doi: 10.1098/rsta.2010.0042)

Slater, L., Jull, M., McKenzie, D. \& Gronvöld, K. 1998 Deglaciation effects on mantle melting under Iceland: results from the northern volcanic zone, Earth Planet. Sci. Lett., 164, 151-164.

DeMets, C., Gordon, R. G., Argus, D. F. \& Stein, S. 1994 Effect of recent revisions to the geomagnetic reversal time scale on estimates of current plate motions. Geophys. Res. Lett. 21, 2191-2194.

Jakobsdóttir, S. S., Roberts, M. J., Guðmundsson, G.B., Geirsson, H. \& Slunga, R. 2008 Earthquake swarms at Upptyppingar, North-East Iceland: a sign of magma intrusion? Studia Geophysica et Geodaetica, 52, 513-528.

Soosalu, H., Key, J., White, R. S., Knox. C., Einarsson, P. \&Jakobsdottir, S. 2010 Lower-crustal earthquakes caused by magma movement beneath Askja volcano on the north Iceland rift. Bull. Volcanol. 72, 55-62. (doi 10.1007/s00445-009-0297-3)

White, R.S., Drew, J., Martens, H. R., Key, J., Soosalu, H. \& Jakobsdottir, S. S. 2011 Dynamics of dyke intrusion in the mid-crust of Iceland, Earth and Planetary Science Letters, 304, 300-312. (doi:10.1016/j.epsl.2011.02.038)

\section{Figure and table caption}

Table 1. Material parameters of the preferred three-dimensional Earth model by Arnadottir et al. (2009), based on the fit to nation-wide GPS measurements of the 
present day vertical uplift of Iceland.

Table 2: Parameters of ice, Earth and magma chamber model used to model the effect of retreat of the sMýrdalsjökull icecap on a shallow magma chamber at Katla volcano.

Figure 1. Rate of pressure change beneath Iceland due to ongoing glacial unloading (see text). Compression positive. Icecaps (closed outlines) are shown on the surface, as well as the fissure swarms of the volcanic zones. Vatnajökull is the largest ice cap.

Figure 2. Melt production rates due to GIA decompression in Iceland integrated from the solidus depth, as a function of depth. Red line displays results for a ridge angle of $45^{\circ}$, blue line for a ridge angle of $60^{\circ}$ and black line for a ridge angle of $70^{\circ}$.

Figure 3. Contribution to express pressure in a dyke, $\Delta P_{d y k e}$, due to ice loss from all Icelandic ice caps between 1890 and 2003. a) location of Vatnajökull ice cap in Iceland. Black dots show relocated earthquake epicentres during 2007 in the Upptyppingar area in relation to a deep dyke intrusion (Jakobsdóttir et al., 2008). Blue lines indicate pre-existing eruptive fissures parallel to the ice cap edge, and yellow regions outline volcanic systems. The black rectangle outlines the region shown in Figure 4. b) a cross-sectional view of $\Delta P_{d y k e}$ for dykes perpendicular to $\sigma_{3}$ imparted by the ice loss. Short ticks show the orientation of $\sigma_{3}$ projected onto the section and the long ticks indicate the dyke plane. c) $\Delta P_{d y k e}$ for dykes perpendicular to plate spreading.

Figure 4. Deformation due to lower crustal intrustion at Upptyppingar, north of Vatnajökull ice cap. Satellite radar interferogram from Envisat descending track 467 spanning 14 July 2007 to 28 June 2008. Each colour fringe represents $28 \mathrm{~mm}$ of displacement toward the satellite. Horizontal GPS velocities, observed in black, with 95\% confidence ellipses, and modelled in white. Also shown are the surface projections of the model patches of the inferred inclined dyke (white rectangles), and catalogue earthquake epicentres for the entire intrusion period from the Icelandic Meteorological Office (black circles).

Figure 5: Model setup for evaluating surface unloading effects on a shallow magma chamber, applicable to Katla volcano Iceland. a) Themodel is a $100 \times 100 \mathrm{~km}$ box with two media: an elastic upper plate emplaced on the top of a lower viscoelastic part. Parameters taken into account are inidcated (listed in Table 2). Stress conditions applied at boundaries are indicated in grey. b) Zoom of the uppermost $10 \mathrm{~km}$, which shows the characteristic of the unloading event as well as the geometry of the magma chamber.

Figure 6. Model prediction of temporal evolution of failure conditions, of a shallow magma chamber at Katla volcano (see text). a) The failure pressure change, $\Delta P_{\mathrm{r}}$ and b) the magma pressure change, $\Delta P_{c}$, ofthe Katla magma chamber due to the last 120 years of deglaciation at the Mýrdalsjökull icecap. Ice retreat has a constant rate of $4 \mathrm{~m} / \mathrm{yr}$ at distances between 7 and $17 \mathrm{~km}$ from the centre of the ice cap, and starts at time $=0 \mathrm{yr}$. The comparison between the viscoelastic case (black) and model for the same situation for a fully elastic Earth model (red) is shown. c) Temporal evolution of 
$\Delta P_{\mathrm{r}}-\Delta P_{\mathrm{c}}$; this difference between both pressure changes is a key parameter for evaluating the evolution of failure conditions. All parameters used for the calculation are listed in Table 2.

Table 1:

\begin{tabular}{|l|l|l|l|l|}
\hline \multicolumn{1}{|c|}{ Layer } & \multicolumn{1}{|c|}{ Depth $[\mathbf{k m}]$} & Density $\left[\mathbf{k g} / \mathbf{m}^{3}\right]$ & Young's [GPa] & Viscosity [Pa s] \\
\hline Upper lithosphere & $0-10$ & 2800 & 40 & $\infty$ \\
\hline Lower lithosphere & $10-40$ & 3000 & 70 & $10^{20}$ \\
\hline Mantle & $40-\infty$ & 3200 & 130 & $10^{19}$ \\
\hline
\end{tabular}

Table 2: See separate file 